\title{
Censos y ganados en Antioquia (Nuevo Reino de Granada)
}

\section{Métodos para una historia pecuaria a finales del siglo XVIII}

Erroldak eta aziendak Antioquian (Granadako Erreinu Berria). XVIII. mendeko abere eta abeltzainen historia aztertzeko metodoak

Censuses and cattle in Antioquia (New Kingdom of Granada). Methods for a livestock history in the late 18th century

\author{
Mauricio Alejandro Gómez Gómez \\ Universidad de Antioquia (Medellín, Colombia) \\ malejandro.gomez@udea.edu.co \\ orcid.org/0000-0003-4021-2027

\section{Resumen}

Este artículo estudia la historia social de los ganados y sus dueños en Antioquia a finales del siglo XVIII. La fuente son los censos ordenados por el visitador Juan Antonio Mon y Velarde entre 1786 y 1787 . El análisis cuantitativo contrastado con registros cualitativos como visitas, mortuorias y pleitos, permitió reconocer vínculos entre la posesión de ciertos ganados, el nivel socio-económico y las formas de distinción y exclusión social. La historia de los animales domésticos nos cuenta aspectos desconocidos de sus dueños, sus aspiraciones, simbolismos, preferencias y condiciones de vida..

\section{Palabras clave}

Historia social; historia colonial; animales domésticos; reformas borbónicas.

\section{Sumario}

INTRODUCCIÓN. EL "REFORMISMO BORBÓNICO» Y LA LLEGADA DE LA FELICIDAD. 1. GANADO BOVINO Y PODER ECONÓMICO 2. EQUINOS Y MULARES: TRANSPORTE Y COMERCIO. 2.1. Caballos Y movilidad. 2.2. Burros y prestigio social. 2.3. Mulas y arriería. 3. GANADO MENOR: CRÍAS DE SUBSISTENCIA Y DE DISTINCIÓN. 3.1. Cerdos y marginación. 3.2. Ovejas y cabras: animales curiosos. CONCLUSIONES. BIBLIOGRAFía. 


\begin{abstract}
Laburpena. Artikulu honetan, XVIII. mende bukaeran Antioquian bizi ziren abeltzain eta abereen historia soziala aztertzen da. Ikerketaiturri gisa, Juan Antonio Mon y Velarde bisitariak 1786 an eta 1787 an agindutako erroldak erabili dira. Analisi kuantitatiboak erregistro kualitatiboekin alderatu dira, bisita, hil-iragarki eta auziekin adibidez, eta egiaztatu da badirela loturak azienda jakin batzuk haztearen, maila sozioekonomikoaren eta sozialki nabarmentzeko eta baztertzeko moduen artean. Etxe abereen historiak haien jabeen alderdi ezezagunak kontatzen dizkigu: zein itxaropen eta sinbolismo eta nolako lehentasun eta bizi kondizioak zituzten.
\end{abstract}

Gako hitzak. Historia soziala; historia koloniala; etxe abereak; borboi erregeen erreformak.

\begin{abstract}
This article studies the social history of livestock and their owners in Antioquia at the end of the 18th century. The source is the censuses ordered by the visitor Juan Antonio Mon y Velarde between 1786 and 1787 . The quantitative analysis contrasted with qualitative records, such as visits, mortuaries and lawsuits, allowed to recognize links between the possession of certain livestock, the socio-economic level and the forms of social distinction and exclusion. The history of domestic animals tells us unknown aspects of their owners, their aspirations, symbolisms, choices and life conditions.
\end{abstract}

Keywords. Social history; colonial history; domestic animals; Bourbon reforms.

\section{Introducción. E1 «reformismo borbónico» y la llegada de la felicidad}

El oidor Juan Antonio Mon y Velarde (San Martín de Oscos, 1747 / Cádiz, 1791) fue el encargado de implantar el reformismo borbónico en la provincia de Antioquia. Allí ejerció el cargo de juez visitador desde agosto de 1785 hasta octubre de 1788. El visitador encontró una provincia en decadencia. Las ricas ciudades auríferas de finales del siǵlo XVI y principios del XVII (Cáceres, Zaragoza y Remedios) no eran más que pobres caseríos. La mayor parte de la población antioqueña, la cual describió como vaga y miserable, vivía en el centro de la gobernación en tres valles escalonados alrededor de una ciudad o villa. Al occidente, en un valle cálido estaba la ciudad de Santafé de Antioquia (500 m.s.n.m); en el centro, en un valle templado, la villa de Medellín (1495 m.s.n.m); y al oriente, en un valle frío, la ciudad de Rionegro (2130 m.s.n.m). El resto del territorio se componía de bosques y selvas escasamente habitados ${ }^{1}$.

La gobernación de Antioquia fue creada en 1569. En la segunda mitad del siǵlo XVIII su población tuvo un crecimiento considerable. En 1777 se contabilizaron 44167 habitantes, los cuales en 1787 llegaron a ser 56072 y, en 1797, ya habitaban la provincia 70855 personas. Este aumento poblacional puede atribuirse a la estabilidad económica de los pequeños propietarios mestizos y mulatos libres, a las mejores condiciones de vida de los esclavos, y al descenso de la mortalidad indígena gracias los cambios en el régimen de trabajo ${ }^{2}$.

1 Uribe y Álvarez, 1998, pp. 57-58.

2 Patiño Millán, 1988, p. 69. 


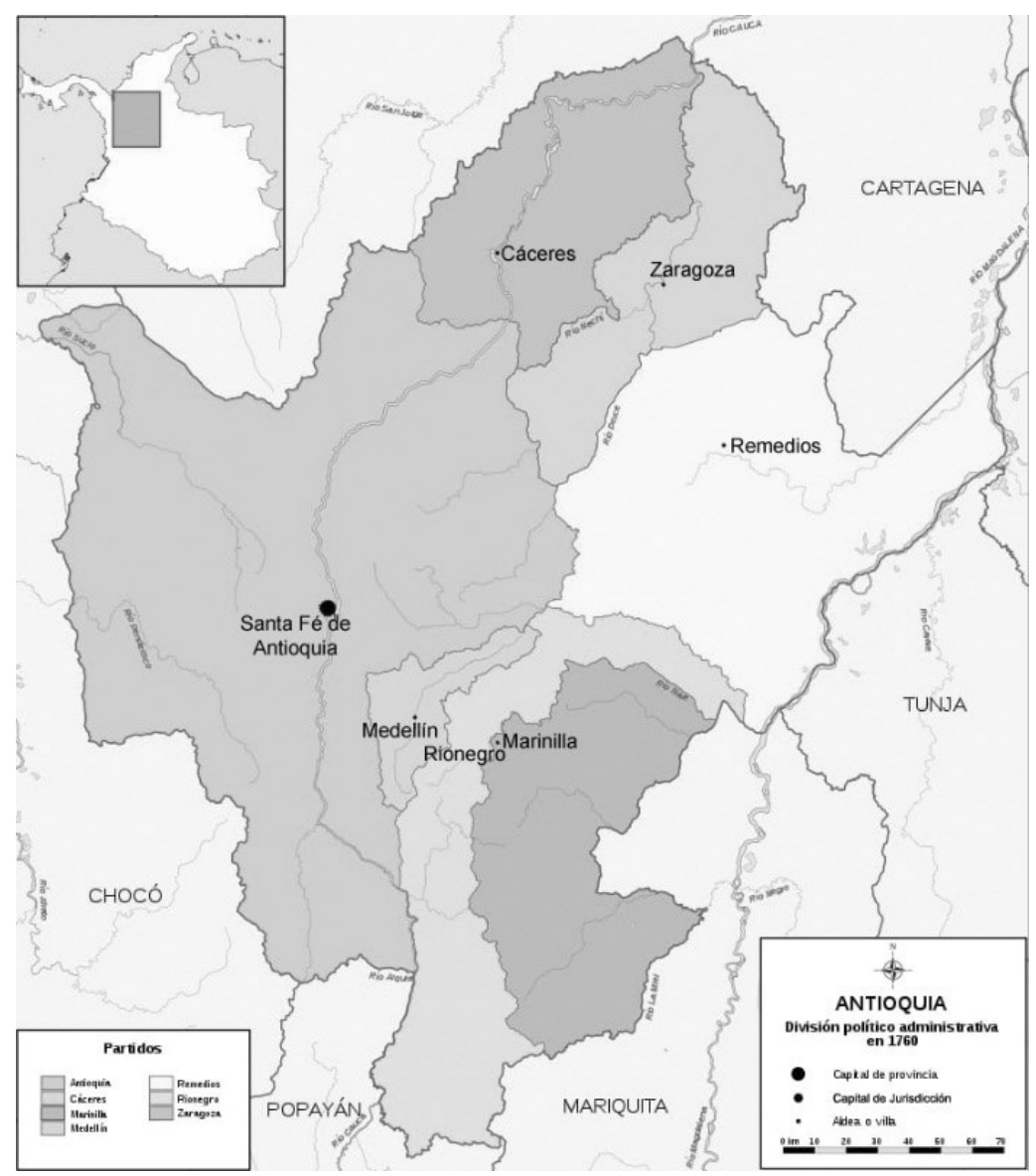

Mapa 1. Antioquia en la segunda mitad del siglo XVIII

Fuente: https://es.wikipedia.orǵ/wiki/Historia_territorial_de_Antioquia [consultada el 11/08/2020].

Antioquia se ubica en el centro-occidente de la actual Colombia sobre las cordilleras central y occidental de los Andes. A finales del siǵlo XVIII la provincia se componía de siete jurisdicciones cuyo centro era una ciudad o villa que ejercía autoridad sobre sitios y pueblos de indios. La jurisdicción de Santafé de Antioquia, capital de la provincia, abarcaba el occidente del territorio de la gobernación. La jurisdicción de Medellín equivalía al territorio del Valle de Aburrá. A mediados de ese siǵlo fueron aǵregadas a la gobernación las jurisdicciones de Marinilla (1756) y Remedios (1757), lo que facilitó el reordenamiento poblacional y la ampliación de la frontera. Al oriente estaban ubicadas las jurisdicciones de Rionegro y Marinilla. Al norte y este estaban las jurisdicciones de las ciudades de Cáceres, Zaragoza y Remedios $^{3}$. En el mapa 1, se aprecia esta división administrativa.

3 Álvarez Morales, 1988, pp. 53-68. 
En la historiografía colombiana Mon y Velarde ha sido calificado como un gobernante borbónico ejemplar que inició en Antioquia un proceso de «regeneración» administrativa a partir de la rigurosidad del recaudo fiscal, el mejoramiento de las comunicaciones, el estímulo de la minería aurífera y el fomento de otras actividades económicas (agricultura, ganadería e industria). Esta era, según el oidor, la forma de traer felicidad a los pueblos: «Es la buena administración uno de los mayores bienes que pueden gozar los pueblos, haciéndolos felices: de este principio nace la quietud pública, por el respeto a los superiores y el amor a los soberanos» ${ }^{4}$.

Sus primeras acciones se enfocaron en sanear una administración plaǵada por la corrupción y el desgobierno. Para ello procesó a los defraudadores de las rentas, promulgó autos de buen gobierno, orǵanizó los estancos reales (aguardiente, degüuello y tabaco); y, por tener autoridad como representante del Patronato Real, puso fin a los abusos del clero y creó la diócesis de Antioquia 5 .

El visitador se preocupó por modernizar la minería, para lo cual dictó unas nuevas ordenanzas mineras. Un antecesor suyo, el gobernador Francisco Silvestre (1775-1776), había afirmado que las minas de Antioquia cada año producían para la Corona 250000 castellanos de oro (más medio millón de pesos en moneda), procedentes, en su mayoría, de la labor de los «mazamorreros», es decir, mineros de pequeñas cuadrillas que extraían el oro en los placeres de ríos y quebradas en minas de aluvión o de oro corrido, en tanto que no existía una verdadera minería de veta o de socavón, pues faltaba la tecnología requerida para ello ${ }^{6}$.

En cuanto a la ganadería, a Mon y Velarde le extrañó que los antioqueños prestaran tan poca atención a este renǵlón económico. Dentro de sus disposiciones para estimular el aumento del hato ganadero, ordenó que quienes no trabajaran todo su tiempo en la minería, sembraran maíz y criaran ganado bovino y cerdos. El oidor creía que la cría de reses aumentaría la riqueza de la región ${ }^{7}$.

En el día no es tan abundante su número, como pudiera según la fertilidad y buenos pastos que ofrece todo su terreno; esto puede proceder de que las gentes acomodadas no miran con la inclinación o afecto que pudieran este ramo, habilitando los labradores pobres, estableciendo con ellos compañías bajo unas condiciones lícitas, equitativas, y ventajosas a todos; pues el labrador conseguiría por su cuidado y trabajo la leche y el queso, y el comerciante o hacendado la parte correspondiente en la cría y procreo del ganado ${ }^{8}$.

4 Ospina, 1918, pp. 8-9.

5 Robledo, 1954, p. 195.

6 Silvestre, 2011, pp. 140-141.

7 González, 2004, p. 15.

8 Robledo, 1954, p. 190. 
Para fomentar la actividad aǵrícola, Mon creó juntas de aǵricultura en Antioquia, Rionegro y Medellín. De acuerdo con Ann Twinam, las reformas de Mon y Velarde estaban encaminadas a optimizar las actividades económicas de la región para que la economía no descansara solo en la minería. Para ello quería estimular el crecimiento del mercado interno, reducir el poder que ejercían los comerciantes sobre el resto de agentes económicos, facilitar las pequeñas transacciones y consolidar la pequeña y mediana propiedad agrícola y ganadera ${ }^{9}$

Para lograr sus propósitos, el oidor promovió el poblamiento de zonas poco habitadas de Antioquia, de esa forma se acabaría con la pobreza de muchas familias sin tierra que vivían como aǵregados en las propiedades de otros en el centro de la provincia. En 1786 dispuso la fundación de pueblos agrícolas al oriente y norte del Valle de Aburrá (San Luis de Góngora, Carolina del Príncipe, San Antonio del Infante, San Carlos de Priego y San Fernando de Amagá). De esta manera, la población creciente de «libres de todos los colores» tendría acceso a la tierra, aumentaría la producción agrícola y la circulación de bienes ${ }^{10}$.

\section{El censo de Mon y Velarde como fuente histórica de la ganadería antioqueña}

Los censos mandados a levantar entre 1786 y 1787 por el visitador Mon y Velarde son una fuente valiosa para estudiar la historia social del último cuarto del siǵlo XVIII en Antioquia, pues la descripción de bienes aporta datos de su vida material. De acuerdo con Joaquín Escriche censo es «el padrón o lista de la población o riqueza de una nación o pueblo». Esta palabra viene del verbo latino censere, que siǵnifica valuar o tasar, por ello para los romanos el censo era el padrón o lista que los censores hacían de las personas y sus haciendas ${ }^{11}$.

El censo constituía para el visitador una herramienta política para analizar los sectores económicos y sociales de Antioquia. Para ello recopilaba información sobre la calidad de cada cabeza de familia, composición familiar (hijos, cónyuge, agregados), bienes (tierras, viviendas, esclavos, minas, ganados), deudas y caudal líquido. Estos datos permitían tomar decisiones acerca de las reformas que Mon quería implantar.

Desde su creación la provincia de Antioquia tuvo una marcada vocación minera, por lo cual la ganadería ha sido considerada como una actividad marginal en la historiografía de la región. A pesar de ello, la rigurosidad con que fueron consignados los diversos tipos de ganado en el censo evidencia el interés del oidor

\footnotetext{
9 Twinam, 1985, p. 105.

${ }^{10}$ Campuzano Cuartas, 1985, p. 309.

11 Escriche, 1911, p. 431
} 
por promover la cría de ganados, para entonces, una actividad poco desarrollada si se compara con otras regiones del Virreinato del Nuevo Reino de Granada ${ }^{12}$.

Los censos fueron levantados por el alcalde pedáneo de cada sitio o partido, quienes conocían de cerca su localidad; por tanto, puede suponerse que los datos son confiables, aunque es posible que algunas personas ocultaran información, pues desconfiaban de las intenciones con que el oidor mandaba a preguntar por sus bienes. La fuente principal para este artículo fueron los censos de doce localidades del interior de la provincia, los cuales se consultaron en el Archivo Histórico de Antioquia (Medellín, Colombia). De la jurisdicción de la villa de Medellín se estudiaron los censos de Aguacatal, Copacabana, Itaguiuí, Otrabanda, Quebrada Arriba, Río Abajo y San Cristóbal. De la jurisdicción de la ciudad de Rioneǵro, se estudiaron los censos de Rioneǵro, San Vicente Ferrer y Guarne. Y de la jurisdicción de la villa de Marinilla, los censos de Marinilla y El Carmen. Es decir, que se cuenta con la información del centro y oriente de la provincia, pues por desǵracia no se conservaron los censos de Santafé de Antioquia (al occidente) ni los de las ciudades de Cáceres, Zaragoza y Remedios (al nordeste). Los anexos 1 y 2 resumen los ganados registrados en los censos estudiados.

El artículo está dividido en tres partes según el tipo de ganado. En la primera parte se analiza el ganado bovino. En la segunda, el ganado caballar, asnal y mular. En la tercera, el ganado menor, es decir, porcinos, caprinos y ovinos. El objetivo es estudiar el aspecto social de una actividad económica que fue complementaria a la minería, de la cual no se ha ocupado mucho la historiografía, pero que nos muestra el vínculo de los antioqueños con la tierra y la diversificación de la economía regional ante las crisis mineras. En las descripciones de los semovientes traídos durante la conquista española se aprecia la filiación de cada «campiña»o «país» con cierto tipo de cría, las relaciones entre dueños y ganados, y las formas de distinción o segregación según la posesión de ciertos animales domésticos.

\section{Ganado bovino y poder económico}

En las montañas de Antioquia se conformó la raza de ganado «blanco orejinegro» a partir del ganado Bos taurus de Andalucía o Extremadura. La raza «blanca cacereña» es de piel suelta y de cabeza tipo ortoide, con cuernos de base fuerte y

12 Para comparar en términos cuantitativos con una región de notable vocación ganadera, está la región Caribe. El ganado fue el producto con mayor peso en su economía y mercado interno, pues su producción se dirigía a abastecer a Cartagena de Indias. En 1778, dentro de sus murallas y castillos, esta ciudad alberǵaba, entre guarnición y población civil, a 13690 personas. Un censo ganadero realizado en 1776 registró que solo en las zonas más cercanas a Cartagena había 84000 cabezas de ganado. Sourdis Nájera, 1996, p. 40. 
circular dirigidos hacia delante, arriba y los lados. La raza «berrenda andaluza»se denomina así por su color, resultado del cruce de la blanca cacereña con la retinta o negra andaluza. Ambas razas tienen un fenotipo similar al Blanco Orejineǵro, que es un ganado cubierto de pelo blanco, con orejas, piel y mucosas neǵras. Esta raza criolla es atlética, rústica, musculosa y bien proporcionada, producto de los suelos pobres y montañosos del territorio antioqueño ${ }^{13}$.

A la par con la fundación de ciudades mineras a orillas de los ríos Cauca y Nechí, Antioquia (1541), Cáceres (1576), Zaragoza (1581) y Remedios (1560), la introducción de ganado y su crianza fue para los españoles un instrumento de colonización. Establecer la cría de ganado alejaba a los españoles del consumo de animales silvestres, a la vez que ayudaba a sentar la presencia española en las praderas deshabitadas y era una forma de cristianización del territorio y de los indígenas ${ }^{14}$.

En la conformación de la provincia de Antioquia la fundación de las primeras ciudades respondía a la búsqueda de oro, de ahí su ubicación en zonas bajas y cálidas. Mientras que en las zonas altas y frías no hubo fundaciones españolas. Algunos españoles vislumbraron las posibilidades ganaderas de aquellas tierras después de la desaparición de gran parte de la población indígena que las habitaba, entre ellos Gaspar de Rodas, segundo gobernador, a quien el cabildo de Santafé de Antioquia le otorgó una merced de tierras en el Valle de Aburrá en 1574. Tras ese hecho, otros ricos propietarios y comerciantes de aquella ciudad también fueron a establecer sus hatos de ganado ${ }^{15}$. La decadencia minera del siǵlo XVII empujó la migración hacia el Valle de Aburrá en búsqueda de nuevas alternativas económicas. De este modo, se contó con una población numerosa que propició que en 1675 se erigiera allí la villa de Medellín ${ }^{16}$.

De acuerdo con los censos de población estudiados, a finales del siǵlo XVIII, 1546 habitantes del centro y oriente de Antioquia poseían 19179 cabezas de ganado vacuno. Pese a que esta cantidad denota la precariedad de la ganadería, al analizar los datos encontramos aspectos dicientes de esta actividad. El 74,9\% (1158) de los dueños apenas tenía el 25,7\% (4934) de los bovinos, se trataba de los poseedores de una a diez cabezas de ganado, quienes en promedio contaban con 4.26 reses cada uno. Según esto, predominaba la pequeña propiedad agrícola y ganadera. Al mismo tiempo, ello indica que la mayor parte de los ganados estaba en manos de pocos propietarios, quienes, por lo tanto, tenían grandes extensiones de tierra. Veámoslo más en detalle: solo 74 personas poseían entre 50

\footnotetext{
13 Pinzón Martínez, 1984, pp. 98-123.

14 Castaño Pareja, 2006, p. 272.

${ }^{15}$ Botero Herrera, 1996, pp. 5-6.

${ }^{16}$ Patiño Rodríguez, 1963, p. 230.
} 
y 500 cabezas de ganado, estos equivalían al 4,87\% de propietarios de ganados, pero eran dueños del $41,39 \%$ de los vacunos (7938 cabezas).

De los cuatro mayores propietarios de ganado mayor tres vivían en el Valle de Aburrá: don Juan Iǵnacio López de la Sierra, registrado en el censo de la Otrabanda, vivía en una casa de teja en la orillas de la quebrada de Iǵuaná, donde cultivaba maíz, frijoles y plátano. Con sus 48 esclavos trabajaba sus tierras en las jurisdicciones de Medellín y Antioquia. En su propiedad del Aguacatal tenía 500 cabezas de ganado ${ }^{17}$. En el Río Abajo, donde predominaba la mediana y ǵran propiedad de la tierra, dos grandes poseedores de ganado tenían 300 reses cada uno, ellos eran Gabriel Muñoz y Joaquín Cadavid, quienes para mantener explotaciones ganaderas extensivas requerían unas 600 hectáreas de tierra cada uno ${ }^{18}$.

El censo permite hacer una comparación de la ganadería entre el centro y el oriente de Antioquia. Se aprecia que a finales del siǵlo XVIII en el Valle de Aburrá aún existía la tradición ganadera de grandes hatos de ganado. Allí había 501 propietarios con 7482 cabezas de ganado. En las localidades del oriente la situación era diferente, allí 1045 poseedores tenían 11697 vacunos. Es decir, que en el oriente, por ser una región de más reciente poblamiento, predominaba la pequeña y mediana propiedad. De acuerdo con esto, la ciudad de Rionegro era el lugar más ganadero de la provincia, allí había 5473 reses que equivalían al 67,42\% de los vacunos de esa jurisdicción y al 28,5\% del ganado de Antioquia ${ }^{19}$.

La actividad ganadera estaba repartida entre una gran cantidad de pequeños propietarios que tenían una menor proporción del ganado vacuno, mientras que un escaso número de dueños poseía la mayor parte de los bovinos. El anexo 1 nos muestra que el bovino era el tipo de ganado más numeroso en los censos analizados. Una forma de averiguar la riqueza a la que equivalía la posesión de estos animales es consultar los valores que contienen las mortuorias del siǵlo XVIII. Una valoración común asignada al ganado vacuno ese siglo era de seis pesos y seis tomines por cabeza. Debido a que Antioquia era una región con una importante minería aurífera, allí la moneda corriente fue el peso de oro en polvo (o castellano) compuesto por ocho tomines, por lo común de una ley de 13 a 18 quilates. Como ejemplo, en 1772, 82 reses de Francisco Hoyos Chavarría fueron avaluadas en 553 pesos y cuatro tomines (seis pesos y seis tomines por res en pie) ${ }^{20}$.

Lo anterior nos ayuda a comprender que la posesión de ganado era una manifestación del poder económico y político. Ejemplo de ello es la familia Álvarez del Pino, cuyos integrantes fueron grandes poseedores de ganados y tierras en

${ }_{17}$ AHA, Estadísticas y censos, vol. 340, doc. 6503, fols. 340-367.

18 AHA, Estadísticas y censos, vol. 340, doc. 6503, fols. 252r-273v.

19 AHA, Estadísticas y censos, vol. 341, doc. 6521, fols. 31r-122v.

${ }^{20}$ AHA, Mortuorias, vol. 236, doc. 5345, fol. 376v. 
Antioquia en los siǵlos XVII y XVIII. Entre los veinte mayores propietarios de ganado bovino, registrados en el censo de la Otrabanda, siete pertenecían a esa parentela. El fundador de esta familia fue don Diego Álvarez del Pino quien, al morir en 1661, dejó un hato en el Valle de Aburrá avaluado en 3100 pesos de oro en polvo y tierras de montaña en la Culatilla y el Picacho, donde pastaban 24 cabezas de ganado vacuno y 12 cabezas de ganado caballar. Uno de los herederos de don Diego, el capitán Mateo Álvarez del Pino, conformó en la Otrabanda un hato ganadero en donde mantenía, según testamento otorgado en 1668, 1300 reses, 70 caballares, 2 mulares y 7 yuntas de bueyes. En su hato y en su estancia de caña dulce contaba con mano de obra esclava ${ }^{21}$. Sus descendientes, según el censo, eran: Juan Lorenzo, que tenía 184 cabezas de ganado; José Iǵnacio, que poseía 135 reses y 5 yuntas de bueyes; Ana María, que contaba con 140 reses y 3 yuntas de bueyes; María Antonia, que tenía 95 reses; Rafael, 73; Iǵnacio, 68, e Isabel Álvarez del Pino, quien tenía 45 reses $^{22}$.

\section{Equinos y mulares: transporte y comercio}

\subsection{Caballos y movilidad}

Los caballos que llegaron a América procedían de la raza andaluza. Aquí se reprodujeron en gran cantidad por la abundancia de pastos y forrajes durante todo el año. En un inicio poseer un caballo era símbolo de alto nivel social, por ello los españoles se esmeraban por cuidarlos, así que ni siquiera los empleaban para cargáar, por lo cual los indígenas debían desempeñar esa labor ${ }^{23}$.

En el siǵlo XVIII el caballo ya no era portador de esa idea de «hidalguía». La significación del ganado caballar para la sociedad antioqueña era diferente, pues su importancia radicaba en que eran útiles para las labores agrícolas y como medio de transporte. La mayoría de los grandes propietarios poseían un buen número de caballos, yeguas y mulas que utilizaban para transportar los productos de sus haciendas, llevar mercancías a las zonas mineras y sacar el producto de las $\operatorname{minas}^{24}$.

De acuerdo con los censos analizados, 2200 personas poseían 9779 caballos y yeguas. Casi el 60\% de estos semovientes se encontraba en la jurisdicción de Medellín. Alrededor de un 30\% estaban en la jurisdicción de Rionegro y un 10\% perte-

\footnotetext{
${ }^{21}$ Patiño Millán, 2011, pp. 138-143.

${ }^{22}$ Arango Mejía, 1993, vol. I, pp. 45-58.

${ }^{23}$ Burcher de Uribe, 1996, p. 159.

${ }^{24}$ Patiño Millán, 2011, p. 159.
} 
necía a la de Marinilla. Es comprensible esta cantidad destacada de caballares en el Valle de Aburrá, pues allí se habían conformado grandes propiedades que eran lugares de producción y transporte de víveres hacia las zonas mineras. Allí se destaca Río Abajo en donde cada propietario, en promedio, era poseedor de ocho caballos.

El incremento de la cría de ganado caballar en el Valle de Aburrá durante el siǵlo XVIII fue resultado del crecimiento en las labores aǵrícolas y comerciales en Antioquia. Según Gloria Bonilla, en 1700 había 1220 caballos, yeguas y mulas, cuyo número en 1730 llegó a 3263. Esto denota el interés de los propietarios de hatos por fomentar la cría de equinos, principal insumo de comerciantes y transportadores de productos agrícolas, textiles, metales y otras mercancías que formaban el circuito comercial de la provincia. Los caballos también eran utilizados como fuerza motriz para los trapiches ${ }^{25}$.

La necesidad de tener caballos para transporte y trabajo en la pequeña propiedad se aprecia en que gran parte de los propietarios (2058 que equivalen al $93,72 \%)$, poseía entre uno y diez equinos, y eran dueños del 63,67\% de ellos (6226 animales). Esto puede indicar que el ganado caballar tenía un costo asequible para muchas familias. Según las fuentes, durante el siglo XVIII un precio promedio de los caballos estaba entre siete y ocho pesos de oro en polvo. Por ejemplo, en 1755 Juan de Ortega y Urdanegui poseía en Hatogrande 37 caballos que fueron avaluados cada uno en siete pesos. Las yeguas alcanzaban precios menores. Este mismo propietario tenía 136 yeǵuas que se valoraron en 340 pesos, cada una en dos pesos y cuatro tomines ${ }^{26}$.

\subsection{Burros y prestigio social}

En los reinos de Hispanoamérica el burro era usado para viajes cortos, llevar pequeñas cargas, y hacer trabajos moderados. Por ser más pequeño que el caballo y la mula, su crianza, empleo y mantenimiento estaba al alcance de los pobres y podía ser manejado por mujeres y niños ${ }^{27}$. En Antioquia los burros tenían un alto valor y, por ello, no eran utilizados para llevar cargas, según lo contaba en la década de 1770 el gobernador Francisco Silvestre:

Las burras y burros que en todas partes son las que más cargan y sirven, a lo menos en lo que interesa al servicio doméstico, son aquí los que nada trabajan, porque las burras sólo las tienen para que les paran garañones: quise

\footnotetext{
${ }^{25}$ Bonilla Vélez, 1984, pp. 180-181.

${ }^{26}$ AHJM, doc. 3181, fol. 14r.

27 Tudela de la Orden, 1993, p. 215.
} 
comprar dos para cargar agua y que viesen lo mucho que podrían servir estos animales y por falta de tiempo y porque no he encontrado quien sepa hacer unas angarillas, lo he dejado, aunque cada burra cuesta aquí diez castellanos o veinte patacones ${ }^{28}$.

Los burros eran un bien altamente valorado. En Antioquia eran utilizados para la procreación de mulas, en el caso de los burros «hechores», y en la gestación de pollinos en el caso de las burras. Al respecto, se tiene como ejemplo que en 1793 un burro hechor de don Antonio Franco y Gordon, en San Jerónimo, fue avaluado en 100 pesos de oro en polvo $^{29}$. Esa alta valoración se debía a que el burro era un bien escaso, lo que se aprecia en los censos estudiados, donde se contaron tan solo 27 burros en manos de 21 propietarios.

El mayor propietario de burros registrado en el censo vivía en la Otrabanda del río Aburrá o Medellín, se trataba del presbítero Salvador Lorenzo de Isaza, quien poseía en sus 48 cuadras de tierras seis asnos. Este hombre de Dios contaba con una considerable cantidad de animales, entre ellos reses (26), ovejas (28), cerdos (24), caballares (58), mulas (8) y bueyes (6). También en la Otrabanda vivía don Iǵnacio Álvarez del Pino quien poseía dos burros hechores y un pollino. Este propietario también tenía reses, caballos, yeguas, potros, mulas, muletos y yuntas de bueyes ${ }^{30}$.

Estos dos personajes, y el resto de sus propiedades, pueden ser muestra del nivel económico de los poseedores de burros y la especie de distinción social que podía significar la tenencia de estos animales. Entre otros dueños de burros en la provincia, que apenas tenían un borrico, se cuentan: un alcalde ordinario y el alférez real de Rioneǵro, el alguacil mayor de Río Abajo y unos inteǵrantes de la mencionada familia Álvarez del Pino.

\subsection{Mulas y arriería}

La mula es un animal híbrido estéril resultado del cruzamiento entre la yegua (Equus caballus) y el burro o asno (Equus asinus). El ganado mular tuvo un crecimiento más lento en América pues su reproducción, por ser artificial, solo es posible en domesticidad completa. El burro semental necesita ser adiestrado para acostumbrarse a las yeguas, así como estas al garañón. Se le llama «mula fina»al híbrido resultante del cruce entre un burro «hechor» y una yegua. El burdégano o

\footnotetext{
${ }^{28}$ Silvestre, 2011, p. 139.

29 AHA, Mortuorias, vol. 216, doc. 5109, fol. 265v.

${ }^{30}$ AHA, Estadísticas y censos, vol. 340, doc. 6503, fols. 340-367.
} 
«mula roma» es el resultado del cruce entre caballo y burra, el cual es más burdo. Las mulas son aptas para silla, carga o tiro. Son muy apreciadas por su seguridad en terrenos montañosos o difíciles. Se acostumbra nombrar «mula» a la hembra mular, «macho»al mulo, $\mathrm{y}$ «muletos» $\mathrm{y}$ «muletas» a los ejemplares jóvenes ${ }^{31}$.

En Antioquia las mulas alcanzaban altos valores debido a que buena parte de ellas debía importarse desde la gobernación de Popayán, pues en la provincia fue difícil consolidar su cría. Esto puede verificarse en el estudio de registros de mercancías de Medellín realizado por la historiadora Beatriz Patiño. Según sus datos, entre 1763 y 1809, 71 personas introdujeron a la villa de Medellín 2675 mulas procedentes de Popayán. El mayor introductor de mulas en esos años fue Miguel María Uribe, quien entre 1785 y 1801 ingresó a Medellín y Rioneǵro 457 mulas traídas desde Popayán ${ }^{32}$.

El precio de las mulas superaba los veinte pesos de oro, aunque variaba según su calidad. De acuerdo con esto, en 1767, se avaluaron en Copacabana 11 mulas de Jerónimo Osorio, ocho de ellas «mulas buenas» en 22 pesos y cuatro tomines, y las otras tres por ser viejas en 12 pesos cada una ${ }^{33}$. Años después, en 1785, el mencionado Miguel María Uribe trajo a Medellín 12 mulas que se valoraron en 240 pesos, es decir, a 20 pesos cada una $^{34}$.

Según los censos, en el centro y oriente de Antioquia en aquellos años existían 1.655 ejemplares mulares poseídos por 250 personas. Similar a los datos de los caballares, alrededor del 60\% de los mulares estaban en la jurisdicción de la villa de Medellín, donde había 970 mulas. En el estudio del ganado mular cobra importancia la localidad de Copacabana. En su censo se registró que 32 propietarios eran dueños de 441 mulas, que equivalían a casi la mitad de las mulas de Medellín y una cuarta parte de los mulares de Antioquia. Copacabana era reconocida porque la arriería era su principal actividad económica, para lo cual eran imprescindibles las mulas.

En Copacabana, Juan Hernández Zapata, un destacado arriero e introductor de mercancías, era propietario de 70 mulas que mantenía en sus tierras, compuestas por 36 cuadras en el Valle Abajo, seis cuadras en El Espinal, cuatro almudes en el Ancón, media legua en Potrero Grande, una cuadra en Copacabana y 18 cuadras en Piedras Blancas. Tenía, además, 88 reses, 20 caballos y 22 esclavos. Sus bienes sumaban 9010 pesos $^{35}$.

31 Alzate, 2001, p. 66.

${ }^{32}$ Patiño, «Comerciantes de Medellín, 1763-1810»(AHA, Libros de Real Hacienda, Aguardiente, Documentos generales y Comercio).

33 AHJM, doc 3622, fol. 9v.

${ }^{34}$ Patiño, «Comerciantes de Medellín...», (AHA, Libros de Real Hacienda, tomo 485, leǵs. 165 y 168).

${ }^{35}$ AHA, Estadísticas y censos, vol. 336, doc. 6476, fols. 536-567. 
Mon y Velarde se percató de que la arriería era la actividad económica más importante en Copacabana, como lo indica la siguiente cita de la Sucinta Relación, documento escrito que da cuenta de las apreciaciones y disposiciones de su visita:

El sitio de Copacabana, conocido comúnmente por el nombre de Tasajera desde su antigüedad es uno de los mejores y más numerosos de toda la provincia. Su situación es amena, en las orillas del río que baja de la villa, de la que dista tres leguas, gozando del mismo clima y temperamento, pero no de igual fertilidad en el terreno, hay algunos sujetos de caudal, y se hace bastante comercio, pero el principal tráfico a que se dedican es de la arriería para sacar cargas desde el Puerto de Nare, así para Su Majestad, como para los particulares ${ }^{36}$.

\section{Ganado menor: crías de subsistencia y de distinción}

\subsection{Cerdos y margiinación}

El cerdo fue el primer ganado europeo que se crio en América, procedente de unos puercos embarcados en La Gomera (islas Canarias) en el segundo viaje de Colón en $1493^{37}$. El cerdo era un elemento de distinción en la cultura de los españoles. Los judíos y musulmanes de la Península tenían prohibido el consumo de carne de cerdo y, por tanto, no lo criaban, mientras que los cristianos lo consumían en abundancia, pues de esa forma se demostraba la diferencia entre cristianos e infieles ${ }^{38}$.

Pese al gusto de los españoles por comer carne de cerdo, al parecer en el Nuevo Mundo su significación sufrió cambios. En los censos estudiados del centro y oriente de Antioquia fueron registrados 5815 cerdos correspondientes a 893 propietarios. Esta escasa cantidad podría deberse a que muchos cerdos no se declararan porque no eran ganados mayores, así mismo, en las mortuorias pocas veces los avaluaron. Un indicio de que la cría de cerdos era una actividad marginal es que el $85 \%$ de sus propietarios (758), tenían entre uno y diez puercos, lo cual componía el 60,9\% de los porcinos de la provincia (3543 animales) y en promedio estos poseedores contaban con 4,7 cerdos por dueño.

San Vicente Ferrer, ubicado al oriente de Antioquia, era el lugar donde había mayor número de cerdos, 1490 en manos de 185 dueños, que equivalían a una cuarta parte de los porcinos de Antioquia. Lo particular de esta localidad es que la mayor parte de los criadores de cerdos pertenecían a la categoría de los «cuar-

\footnotetext{
${ }^{36}$ Robledo, 1954, t. II, p. 308.

37 Patiño Rodríguez, 1963, p. 295.

38 Oliveros de Castro y Jordana de Pozas, 1968, p. 218.
} 
terones y mestizos». Estos representaban el 69,7\% de los propietarios (129) y tenían el $64 \%$ de los cerdos (956). De lo que se puede colegir que era una cría de subsistencia de los individuos con menores recursos económicos ${ }^{39}$.

Menos de una tercera parte de los cerdos se encontraban en el Valle de Aburrá (1625). Allí estaba la localidad que tenía menos ganado porcino. Se trataba de Río Abajo, en donde apenas había 10 propietarios y 93 cerdos. Esto se debía a la prevalencia de la gran propiedad de tierras dedicadas a los vacunos (1491 cabezas) y caballares (1274 bestias). Por ello, entre los poseedores de cerdos que registró el censo se contaban jornaleros y aǵregados que no poseían tierras ${ }^{40}$. Según esto, los cerdos proliferaban en zonas de pequeña propiedad junto con cultivos de pan coger; mientras que, donde había grandes hatos ganaderos su cría no era tan apetecida.

Un pleito de finales del siǵlo XVIII nos puede ayudar a comprender ese cambio en la consideración hacia los cerdos. En 1788 algunos vecinos pobres de la ciudad de Antioquia solicitaron, para mejorar su cría de cerdos, permiso para disponer del agua de la acequia que venía del río Tonusco. El gobernador Francisco de Baraya rechazó su petición, basado en las medidas promulgadas por el visitador Mon y Velarde, pues conceder lo que pedían sería derogar dicho mandato y «se vería todo el lugar lleno en poco tiempo de estos animales inmundos y propiamente puercos no consentidos en ninguna ciudad ni lugar medianamente civilizado» ${ }^{41}$.

El cerdo había perdido la significación que tenía en España y durante la conquista. El crecimiento de la ganadería vacuna promovió el ascenso social de una élite de propietarios españoles con poder económico y político, así que el consumo de carne de res le iba mejor a las pretensiones de un estilo de vida de mayor categoría ${ }^{42}$. De esta forma, se marcó una distinción entre consumir carne vacuna y porcina. Los criadores y consumidores de cerdos, pobres en su mayoría, llegaron a ser receptores del desprecio hacia aquellos animales «puercos»e «inmundos».

\subsection{Ovejas y cabras: animales curiosos}

Las ovejas domésticas (Ovis aries) y las cabras (Capra hircus) son dos especies distintas de la familia Bovidae. Están entre los primeros animales que fueron domesticados. Las ovejas para lana y carne, y las cabras para leche y carne ${ }^{43}$. Francisco Silvestre llamó la atención sobre lo conveniente que sería criar ovejas

\footnotetext{
39 AHA, Estadísticas y censos, vol. 343, doc. 6536, fols. 1r-56r.

${ }^{40}$ AHA, Estadísticas y censos, vol. 340, doc. 6503, fols. 252r-273v.

${ }^{41}$ AHA, Policía, vol. 69, doc. 1872, fols. 219r-220v.

42 Saldarriaga, 2015, p. 59.

43 Hafez, 1989, p. 341.
} 
y cabras en Antioquia por la calidad de los suelos y la utilidad que podría brindar a sus habitantes; sin embargoo, advertía que este ganado menor era muy escaso. Al respecto decía:

En Rionegro, Marinilla, Medellín, y en otros territorios de la provincia, y aun en esta capital, pudieran mantenerse manadas de ovejas y carneros, y también de cabras; y de éstas especialmente en esta capital (Antioquia), por ser el terreno pedregoso, y escabroso al propósito para su cría. Mas, apenas, hay uno, u otro, que por gusto, o curiosidad mantenga unas pocas de ovejas, o de cabras que nadie ignora, a más de la carne, las utilidades, que trae la lana, la leche, la piel y sus despojos: de modo que si uno compra un carnero del que ellos tienen, lo menos que le cuesta son cinco o seis castellanos de oro, que son diez o doce patacones ${ }^{44}$.

La apreciación del gobernador Silvestre acerca de la cría de ovinos y caprinos en Antioquia era acertada. En el censo de Mon y Velarde se registraron 465 ovejas que eran propiedad de 30 dueños. La mayor parte de estos lanares se encontraban en localidades de clima frío y templado como Rionegro (196 ovejas), Guarne (94) y Otrabanda (61). El mayor poseedor de ganado lanar se encontraba en Rioneǵro, era Nicolás Monsalve Cardona, quien tenía 100 cuadras de tierras de caballería en la Mosca, otras 100 de tierras de pan en el Palmar, 18 cuadras en la Golondrina y doce más en el Abejuco. En ellas tenía 50 ovejas, 65 vacas, doce caballos, 20 cerdos y cinco mulas ${ }^{45}$. Lo que puede indicar que las ovejas no eran su principal ganado, sino que las criaba por un gusto particular.

También fueron censadas 305 cabras que pertenecían a 21 poseedores. Las localidades donde se encontraba este tipo de ganado en mayor número fueron Rioneǵro (169), Río Abajo (87) y Guarne (22 cabras). No es extraño que el mayor poseedor de caprinos se encontrara en Rionegro y que su perfil socioeconómico fuera parecido al del anterior personaje. En esta ciudad el maestro José Antonio Villegas tenía entre sus posesiones una casa de paja en La Ceja, 15 fanegas de tierra, que equivalen a 170,544 hectáreas; 48 cuadras de tierras de sembradura en el paraje de las Yeguas, en las cuales tenía sus ganados grandes y chicos: 80 vacas, 12 caballos, 14 mulas, 25 yeguas y 55 cabras. También tenía 31 esclavos grandes y chicos ${ }^{46}$.

La cría de ovinos y caprinos en el centro y oriente de Antioquia estaba relacionada con la gran propiedad de tierras, pero no constituía una actividad económica por sí misma, sino que eran animales que denotaban el estatus social de sus dueños y eran una afición que demandaba cuidados, pero de la cual se obtenían menos beneficios que del ganado vacuno.

\footnotetext{
${ }^{44}$ Silvestre, 2011, p. 139.

45 AHA, Estadísticas y censos, vol. 341, doc. 6521, fols. 31r -122v.

${ }^{46}$ AHA, Estadísticas y censos, vol. 341, doc. 6521, fols. $31 \mathrm{r}-122 \mathrm{v}$.
} 


\section{Conclusiones}

Los ganados introducidos por los colonizadores españoles, criados bajo las condiciones ambientales propias del Nuevo Mundo, cobraron significados diferentes a los que tenían en la Península. Los censos estudiados del centro y oriente de Antioquia a finales del siglo XVIII dejan ver los signos culturales y sociales de la tenencia de cierto tipo de ganado en esos años en aquella provincia. La ganadería vacuna, de menor importancia en España, se difundió en América hasta convertirse en el principal cárnico consumido por los españoles y en manifestación de la posición económica de sus poseedores.

La posesión de animales de trabajo (caballos, asnos y mulas), expresaba diversos significados. El caballo, símbolo de hidalguía en un inicio, al proliferar su cría vio abaratado su precio, así que los grupos bajos, que lo requerían para transporte y trabajo, tuvieron acceso a estos equinos. Los asnos o burros tenían una consideración especial en la Antioquia borbónica, en donde eran animales de lujo y distinción, y no eran usados para trabajar. Las mulas tenían un alto valor comercial y eran el principal medio de carga de arrieros y comerciantes, quienes integraban todas las actividades económicas de la región.

El ganado menor presentaba grandes contrastes en Antioquia. Los dueños de cerdos eran marginados por su pobreza, una de las tantas formas de exclusión de la sociedad colonial. Las ovejas y cabras no tuvieron importancia económica en el centro-oriente de la provincia, sino que eran crías curiosas de algunos poseedores de ganado mayor, cuyos productos, carne, leche, lana y cordobán, quizás iban al consumo doméstico.

La historia de los animales da cuenta de las representaciones construidas por sus dueños. En este caso, se establecen relaciones entre propietarios y ganados, y la significación social de tener cierto tipo de animal, de lo cual se derivan formas de distinción y de marǵinación.

\section{Bibliografía}

\section{Fuentes primarias}

Archivo Histórico de Antioquia (AHA):

Estadísticas y censos, vols. 336, 337, 338, 340, 341, 343.

Mortuorias, vols. 216, 236.

Policía, vol. 69.

— Beatriz Patiño Millán, «Comerciantes de Medellín, 1763-1810» (AHA, Libros de Real Hacienda, Aguardiente, Documentos generales y Comercio).

Archivo Histórico Judicial de Medellín (AHJM): Docs. 3181, 3622. 


\section{Bibliografía secundaria}

Álvarez Morales, Víctor, «La sociedad colonial. 1580-1720», en Jorge Orlando Melo (ed.), Historia de Antioquia, Medellín, Suramericana, 1988, pp. 53-68.

Alzate, Luis Ángel, Nuestros equinos: caballares, asnales y mulares, Medellín, Impresiones gráficas, 2001.

Arango Mejía, Gabriel, Genealogías de Antioquia y Caldas, Medellín, Litoarte, 1993.

Bonilla Vélez, Gloria Estela, «La estructura agraria en el Valle de Aburrá 1676-1730», Medellín, Universidad de Antioquia, 1984 (Trabajo de grado historiadora).

Botero Herrera, Fernando, Medellín 1890-1950, Historia urbana y juego de intereses, Medellín, Editorial Universidad de Antioquia, 1996.

Burcher de Uribe, Priscilla, Origen de los animales domésticos, Medellín, Editorial Universidad de Antioquia, 1996.

Campuzano Cuartas, Rodrigo, «Fundaciones de Yarumal, Sonsón, San Carlos y Amagá», Medellín, Universidad de Antioquia, 1985 (Trabajo de grado historiador).

Castaño Pareja, Yoer, «De bestias y de hombres: la introducción de la actividad ganadera en el Occidente Neogranadino, siglo XVI», Historia y Sociedad, 12, 2006, pp. 251-284.

Escriche, Joaquín, Diccionario Razonado de Legislación y Jurisprudencia, París, Librería de la Viuda de Ch. Bouret, 1911.

González Cardona, Liliana. El desarrollo ganadero de Antioquia entre 1870 y 1920 , Medellín, IDEA, 2004.

Hafez, E. S. E., Reproducción e inseminación artificial en animales, México, Interamericana, 1989.

Oliveros de Castro, María Teresa, y Julio Jordana de Pozas, La agricultura de los reinos españoles en tiempo de los Reyes Católicos, Madrid, Ministerio Instituto Nacional de Investigaciones Agronómicas, 1968.

Ospina, Tulio, «El Oidor Mon y Velarde Regenerador de Antioquia», Repertorio Histórico de la Academia Antioqueña de Historia, 2, 9-11, 1918 [1901], pp. 1-21.

Patiño Millán, Beatriz, «La provincia en el siglo XvıII», en Jorge Orlando Melo (ed.), Historia de Antioquia, Medellín, Suramericana, 1988, pp. 69-90.

Patiño Millán, Beatriz, Riqueza, pobreza y diferenciación social en la Provincia Antioquia durante el siglo XVIII, Medellín, Editorial Universidad de Antioquia, 2011.

Patiño Rodríguez, Víctor Manuel, Plantas cultivadas y animales domésticos en América equinoccial, "Animales domésticos introducidos», Cali, Imprenta Departamental, Tomo V, 1963.

Pinzón Martínez, Emigdio, «Historia de la ganadería bovina en Colombia», Suplemento Ganadero, 4, 1, 1984, pp. 98-123.

Robledo, Emilio, Bosquejo Biográfico del Señor Oidor don Juan Antonio Mon y Velarde, Visitador de Antioquia 1785-1788, Bogotá, Banco de la República, 1954.

Saldarriaga, Gregorio, «Comer y ser. La alimentación como política de la diferenciación en la América española, siglos XVI y XVII», Varia Historia, 32, 58, 2015, pp. 53-77. 
Silvestre, Francisco, Relación de la provincia de Antioquia (Estudio preliminar David J. Robinson), Medellín, Gobernación de Antioquia, 2011 [1788].

Sourdis Nájera, Adelaida, «Estructura de la ganadería en el Caribe colombiano durante el siǵlo XVIII», Huellas. Revista de la Universidad del Norte, 47-48, 1996, pp. 38-48.

Tudela de la Orden, José, Historia de la ganadería hispanoamericana, Madrid, Ediciones de Cultura Hispanoamericana, 1993.

Twinam, Ann, Mineros Comerciantes y labradores en Antioquia, 1763-1810, Medellín, FAES, 1985.

Uribe, María Teresa, y Jesús María Álvarez, Raíces del poder regional: El caso antioqueño, Medellín, Editorial Universidad de Antioquia, 1998. 


\section{Anexos}

Anexo 1. Resumen gánados bovinos y equinos en Antioquia, 1786-1787

\begin{tabular}{|l|r|r|r|r|r|r|r|r|}
\hline \multicolumn{1}{|c|}{ Lugar } & \multicolumn{1}{c|}{ Bovinos } & \multicolumn{1}{c|}{ Dueños } & Caballares & \multicolumn{1}{c|}{ Dueños } & Mulares & Dueños & Burros & Dueños \\
\hline Aguacatal & 1.313 & 102 & 865 & 230 & 91 & 17 & 4 & 3 \\
\hline Carmen & 403 & 53 & 123 & 40 & 2 & 2 & - & - \\
\hline Copacabana & 656 & 43 & 903 & 175 & 441 & 32 & 2 & 2 \\
\hline Guarne & 837 & 145 & 455 & 121 & 10 & 3 & - & - \\
\hline Itagüí & 375 & 79 & 864 & 316 & 49 & 24 & 1 & 1 \\
\hline Marinilla & 3.176 & 274 & 927 & 250 & 186 & 28 & - & - \\
\hline Otrabanda & 3.101 & 129 & 1.397 & 224 & 216 & 36 & 14 & 9 \\
\hline Quebrada Arriba & 301 & 50 & 206 & 59 & 18 & 7 & 1 & 1 \\
\hline Río Abajo & 1.491 & 49 & 1.274 & 159 & 140 & 23 & 3 & 3 \\
\hline Rionegro & 5.473 & 311 & 1.668 & 311 & 351 & 38 & 2 & 2 \\
\hline San Cris tóbal & 245 & 47 & 238 & 104 & 15 & 8 & - & - \\
\hline San Vicente & 1.808 & 264 & 859 & 211 & 136 & 32 & - & - \\
\hline Total & $\mathbf{1 9 . 1 7 9}$ & $\mathbf{1 . 5 4 6}$ & $\mathbf{9 . 7 7 9}$ & $\mathbf{2 . 2 0 0}$ & $\mathbf{1 . 6 5 5}$ & $\mathbf{2 5 0}$ & $\mathbf{2 7}$ & $\mathbf{2 1}$ \\
\hline
\end{tabular}

Fuente: AHA, Estadísticas y censos. Elaboración propia.

Anexo 2. Resumen gáanados menores en Antioquia, 1786-1787

\begin{tabular}{|l|r|r|r|r|r|r|}
\hline \multicolumn{1}{|c|}{ Lugar } & \multicolumn{1}{c|}{ Cerdos } & \multicolumn{1}{c|}{ Dueños } & \multicolumn{1}{c|}{ Cabras } & \multicolumn{1}{c|}{ Dueños } & \multicolumn{1}{c|}{ Ovejas } & \multicolumn{1}{c|}{ Dueños } \\
\hline Aguacatal & 407 & 77 & - & - & 26 & 2 \\
\hline Carmen & 310 & 36 & - & - & - & -25 \\
\hline Copacabana & 102 & 16 & 10 & 1 & 25 & 2 \\
\hline Guarne & 524 & 92 & 22 & 4 & 94 & 5 \\
\hline Itagüí & 291 & 93 & - & - & - & 2 \\
\hline Marinilla & 841 & 92 & 10 & 1 & 23 & 6 \\
\hline Otrabanda & 444 & 82 & 4 & 1 & 61 & 1 \\
\hline Quebrada Arriba & 110 & 35 & - & - & 6 & 2 \\
\hline Río Abajo & 93 & 10 & 87 & 5 & 31 & 8 \\
\hline Rionegro & 1.025 & 132 & 169 & 8 & 196 & - \\
\hline San Cris tóbal & 178 & 42 & - & - & - & 3 \\
\hline San Vicente & 1.490 & 185 & 3 & 1 & 3 & $\mathbf{3 0}$ \\
\hline Total & $\mathbf{5 . 8 1 5}$ & $\mathbf{8 9 2}$ & $\mathbf{3 0 5}$ & $\mathbf{2 1}$ & $\mathbf{4 6 5}$ & \\
\hline
\end{tabular}

Fuente: AHA, Estadísticas y censos. Elaboración propia. 
